\title{
Comparative analysis among three Taiwan-specific Gentiana species and Chinese medicinal plant Gentiana scabra
}

\author{
Shih-Hung Huang ${ }^{1}$, Emily Chin-Fun Chen ${ }^{1}$, Chin-Tung Wu ${ }^{3}$, Chao-Lin Kuo ${ }^{4}$ and Hsin-Sheng Tsay ${ }^{1,2^{*}}$
}

\begin{abstract}
Background: The root of Gentiana scabra is commonly known as Longdan in Chinese herbal medicines and has been used in the treatment of inflammation, anorexia, indigestion and gastric infections for over 2000 years. High market demand had made G. scabra (GS) plants not to be the only source of Longdan in China, other Gentiana spp., G. triflora, G. manshurica and G. rigescens, were also recognized as Longdan in China now.

Results: In this study, we identified three Taiwan-specific Gentiana spp., G. davidii var. formosana (GDF) and G. arisanensis (GA) and G. scabrida var. punctulata (GSP) that are phylogenetically different from GS (main source of Longdan). However, the active compounds of Longdan, gentiopicroside and swertiamari, were found in GSP and GDF showed higher antioxidant ability and free radical scavenging activities than Chinese Longdan. This discovery might explore the medicinal potential of GDF. Meanwhile, another Taiwan-specific Gentiana spp., GSP, was found to have the strongest antioxidant ability and free radical scavenging activities which might suggest a possible use of GSP as a source of natural antioxidant agents for industrial purpose.

Conclusions: The finding of this study indicated that ITS analysis can be used to identify Taiwan-specific Gentiana spp. Also the Taiwan-specific Gentiana spp. which has strongest antioxidant and free radical scavenging activities among others could be a better choice for industrial purpose.
\end{abstract}

Keywords: Antioxidant; Gentiana davidii var. formosana; Gentiana scabra; Gentiopicroside; Longdan

\section{Background}

The genus Gentiana is a large genus comprised about 400 species which are widely distributed in temperate regions of Asia, Europe, the Americas, northwest Africa, eastern Australia and New Zealand (Georgieva et al., 2005; Zając and Pindel, 2011). Gentian root is used in the production of wines, liqueurs, and bitter flavoring in Europe and Australia. In Asia, the root of Gentiana sca$b r a$, is commonly known as Longdan in Chinese herbal medicines and has been used in the treatment of inflammation, anorexia, indigestion and gastric infections (Tang and Eisenbrand, 1992) for over 2000 years. Recent studies indicated that the root extract from Gentian

\footnotetext{
* Correspondence: hstsay@cyut.edu.tw

'Department of Applied Chemistry, Chaoyang University of Technology, Taichung, Taiwan

${ }^{2}$ Department of Agronomy, National Chung Hsing University, Taichung, Taiwan

Full list of author information is available at the end of the article
}

plant can inhibit tumor cell proliferation (Matsukawa et al. 2006), enhance DNA repair, exerts antioxidant activity (Hudecová et al., 2012) and hepatoprotective effect (Ko et al., 2011).

While the market demands for G. scabra (GS) plants have greatly increased over the past decades, their supplies are now in severe shortage due to the overexploitation and ecological destruction of their natural habitats. Now the roots of G. scabra (GS) is not the only source of Longdan in China, but also the roots from other Gentiana spp., G. triflora, G. manshurica and G. rigescens. In Taiwan, there are more than 10 Gentiana spp. Most of them are annual herbs, except G. davidii var. formosana (GDF) and G. arisanensis (GA). Moreover, there is one species with tall phenotype, G. scabrida var. punctulata (GSP) which is sometimes up to $20 \mathrm{~cm}$ while others are less than $15 \mathrm{~cm}$ tall (Chen and Wang, 1999). Hence, we took GDF, GA and GSP as our 
research material in order to explorer their medicinal potential.

Chemical investigation of root extract of Gentiana spp. has resulted in isolation of a series of loganic acid, swertiamarin, gentiopicroside, gentisin and isogentisin (Aberham et al., 2007; Aberham et al., 2011). Gentiopicroside (a secoiridoid glucoside) and swertiamarin are two important active components used for gentian identification.

Another method to identify or differentiate Gentiana spp. is rDNA ITS (internal transcribed spacers) sequence analysis (Ji et al., 2003). The ITS region in rDNAs comprises of ITS1 and ITS2. ITS1 is between the $18 \mathrm{~S}$ and $5.8 \mathrm{~S}$ rDNA, while ITS2 is between the $5.8 \mathrm{~S}$ and $28 \mathrm{~S}$ rDNA. The conserved regions of $18 \mathrm{~S}$ and $28 \mathrm{~S}$ rDNA have been used to design universal primers used to amplify the flanking ITS regions (Wu et al., 2012). Since ITS1 and ITS2 regions can be amplified by using universal primers, and the results are reliable, rDNA ITS sequence analysis was used in our study to understand the phylogenetic relationship of selected Taiwan-specific Gentiana spp. (GDF, GA and GSP) with Chinese Longdan.

Based on the recent studies about the root extract from Longdan in enhancing DNA repair and exerting antioxidant activity, we were also interested in the possible antioxidants such as polyphenols and flavonoids existed in three Taiwan-specific Gentiana spp. (GDF, GA and GSP). Free radicals and reactive oxygen species (ROS) such as superoxide, hydroxyl and peroxyl radicals produced during oxidation (Blokhina et al., 2003) or by exposure to radiation, toxic chemicals, smoking, alcohol and oxidized polyunsaturated fatty acids have been implicated to cause protein, DNA and cell membranes (Farber, 1994) and leading to the development of a variety of diseases such as cardiovascular disease, cancer and other chronic diseases (Willcox et al., 2004). Thus, measurement of total phenolic and flavonoids, as well as antioxidant and free radical scavenging activity have become important tools to study the differences in our three Taiwan-specific Gentiana spp. (GDF, GA and GSP) and Chinese Longdan (GS).

In the present study, the identification of three Taiwan-specific Gentiana spp. (GDF, GA and GSP) based on rDNA ITS sequence analysis and HPLC method was performed. Meanwhile, the ethanol extracts of the roots from three Taiwan-specific Gentiana spp. (GDF, GA and GSP), Chinese Longdan (GS) and ethanol extracts of two market-purchased dried gentian roots (herbal imported from China) were used to characterize their antioxidative potencies, scavenging activities against ABTS and DPPH radicals. The finding of this work may explore the medicinal and industrial potential of Taiwan-specific Gentiana spp.

\section{Methods}

\section{Chemicals}

1,1-Diphenyl-2-picrylhydrazyl (DPPH), phenazine methosulfate (PMS), sodium carbonate, gallic acid (GA), quercetin $(\mathrm{QE}), 2$ 2, 2-azinobis [3-ethylbenzothiazoline- 6-sulfonate] (ABTS), Folin-Ciocalteu's reagent, were purchased from Sigma-Aldrich (St Louis, MO, USA). Swertiamarin and gentiopicroside were purchased from National Institute for Control of Pharmaceutical and Biological Products (Beijing, PR China). All other chemical reagents used were of analytical grade. The DNeasy Plant Mini kit was purchased from Qiagen (Hilden, Germany). The Plasmid DNA purification kit, DNA purification kit and DNA marker were purshased from GeneMark Technology (Tainan, Taiwan). Primers were synthesized by Tri-ibiotech (Taipei, Taiwan). The FastRun Taq Master Mix kit was purchased from Protech Technology Enterprise (Taipei, Taiwan).

\section{Plant material}

The G. scabra (GS) collected from China were grown in the green house of Chaoyang University of Technology (Taichung, Taiwan). G. davidii var. formosana (GDF), G. arisanensis (GA) and G. scabrida var. punctulata (GSP) were collected from Taichung, Nantou, and Jiayi counties in Taiwan (Figure 1). All plant materials were identified by Dr. Chao-Lin Kuo (associate professor and chairman of the Department of Chinese Pharmaceutical Sciences and Chinese Medicine Resources, China Medical University, Taichung, Taiwan). The dried gentian roots (DR1 and DR2) imported from China were purchased from a local medicinal plant market.

\section{DNA extraction, PCR amplification and sequencing}

Genomic DNA was extracted from fresh leaves or dried roots. Approximately $100 \mathrm{mg}$ of samples was pulverized with liquid nitrogen in a mortar and then extracted by DNeasy ${ }^{\circ}$ Plant Mini Kit (Qiagen, Germany). The ITS15.8S-ITS2 regions of tested samples were amplified with the primer pair 18S-F (5'-CGT AAC AAG GTT TCC GTA GGT GA-3') and 28S-R (5'-CCT TTC ATC TTT CCC TCG CGG T-3') (Lin et al., 2007). PCR mixture containing $50 \mathrm{ng}$ of genomic DNA, $1 \mu \mathrm{l}$ of $18 \mathrm{~S}-\mathrm{F}$ primer, $1 \mu \mathrm{l}$ of $28 \mathrm{~S}-\mathrm{R}$ primer and $25 \mu \mathrm{l}$ of Taq Master Mix buffer was made up to $50 \mu \mathrm{l}$ with sterile distilled water. The PCR programme consisted of an initial denaturising step of $5 \mathrm{~min}$ at $94^{\circ} \mathrm{C}$ followed by 35 cycles of $30 \mathrm{~s}$ at $94^{\circ} \mathrm{C}$, $30 \mathrm{~s}$ at $55^{\circ} \mathrm{C}$ and $30 \mathrm{~s}$ at $72^{\circ} \mathrm{C}$ and a final extension step of $10 \mathrm{~min}$ at $72^{\circ} \mathrm{C}$. Approximately $10 \mu \mathrm{l}$ of PCR products were electrophoresed on $1 \%$ agarose gel, stained with ethidium bromide, and visualized under UV. The amplified PCR product was purified using illustra GFX PCR DNA and Gel Band Purification Kit (GE Healthcare Life Sciences) and subsequently sent for sequencing. All 


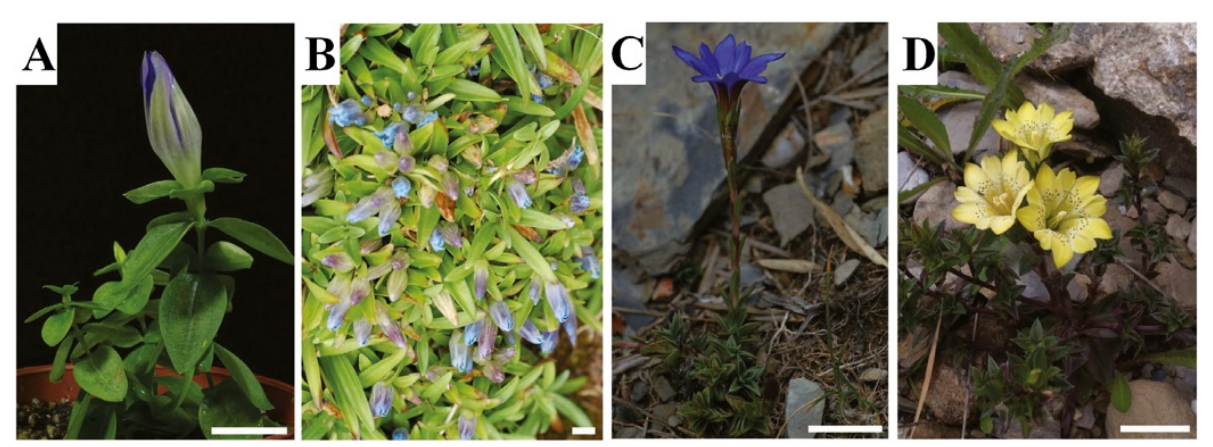

Figure 1 Representative photographs of Gentiana spp. A. G. scabra Bunge; B. G. davidii var. formosana; C. G. arisanensis Hayata; D. G. scabrida Hayata var. punctulata. Bar $=2 \mathrm{~cm}$.

sequences obtained were characterized by using nucleotide blast (http://www.ncbi.nlm.nih.gov).

\section{Phylogenetic analysis}

A total of 7 sequences of the ITS1-5.8S-ITS2 region of different Gentiana species collected from the NCBI databases, together with 3 additional ITS of GDF, GA and GSP obtained in this study were used for phylogenetic analysis. Phylogenetic analysis was performed by using the PHYLIP Version 3.69 (Felsenstein, 1989). Bootstrap analysis with 1000 times replicates (Felsenstein, 1985) of the alignment was applied to maximun parsimony method.

\section{Preparation of root extracts from Gentiana spp.}

All six Gentiana spp. roots were cut into small pieces, freeze-dried (24-48 h), and ground with a blender into fine powder form. Accurately weighed into $5.0 \mathrm{~g}$ aliquots and placed in $15 \mathrm{ml}$ centrifuge tubes. After adding ethanol, the samples were sonicated at $40^{\circ} \mathrm{C}$ for $30 \mathrm{~min}$ and followed by centrifugation. Each sample was extracted three times and all the supernatants were collected and filtrated. Every filtrate was dried and resuspended in ethanol to the final concentration of $10 \mathrm{~g} / \mathrm{l}$.

\section{Determination of swertiamarin and gentiopicroside content}

The HPLC system (Hitachi) equipped with L-2130 binary pump, an L-2200 auto-sampler and an L-2450 PDA-UV detector was used for the determination of swertiamarin and gentiopicroside. Swertiamarin and gentiopicroside were carried out by following the method of (Zhang et al., 2010) with some modifications. The chromatographic separation of analytes was performed at room temperature using a Mightysil RP18 GP column $(250 \times 4.6 \mathrm{~mm} 5 \mu \mathrm{m})$. The mobile phase consisted of $0.2 \%$ phosphoric acid in water (solvent A) and $100 \%$ methanol (solvent B) flow rate of $1 \mathrm{ml} / \mathrm{min}$. In the preliminary experiments, the elution conditions applied are as follows: $0-25 \mathrm{~min}$, linear gradient $80-65 \% \mathrm{~A}$; and, finally, reconditioning steps of the column was $80 \%$ A isocratic for $10 \mathrm{~min}$. Data were collected and analyzed using EZchrom Elite Version 3.13 software. Various concentrations $(1-100 \mathrm{mg} / \mathrm{l})$ made from the standard stock of swertiamarin and gentiopicroside were used for calibration curve.

\section{Determination of total phenolic content}

The amount of total phenolic was determined by the Folin-Ciocalteu method reported (Slinkard and Singleton, 1977) with slight modifications. Each extract (100 mg/l) was mixed with $200 \mu \mathrm{l}$ distilled water and $40 \mu \mathrm{l}$ of Folin-Ciocalteu phenol reagent, incubated at room temperature for $5 \mathrm{~min}$ and then mixed with $40 \mu \mathrm{l}$ of $20 \% \mathrm{Na}_{2} \mathrm{CO}_{3}$. After color development, the absorbance of all samples was measured at $765 \mathrm{~nm}$ using the UV-vis spectrophotometer. Gallic acid was used as standard and total phenolic content were expressed as $\mathrm{mg} / \mathrm{g}$ gallic acid equivalent (GAE).

\section{Determination of total flavonoids}

Total flavonoids were determined by $\mathrm{AlCl}_{3}$ method (Lamaison and Carnet, 1990). $100 \mu \mathrm{l}$ of $2 \% \mathrm{AlCl}_{3}$ was added to $100 \mu \mathrm{l}$ of extract $(100 \mathrm{mg} / \mathrm{l})$. The mixture was vigorously shaken and followed by absorbance measurement at $430 \mathrm{~nm}$. Quercetin was used as standard and total flavonoids were expressed as $\mathrm{mg} / \mathrm{g}$ quercetin equivalent $(\mathrm{QE})$.

\section{Determination of antioxidant activity}

The antioxidant activity was determined by ABTS (Re et al., 1999), DPPH radical scavenging assay (Blois, 1958) and reducing power assay (Oyaizu, 1986).

DPPH radical-scavenging activity was determined as described with slight modification. Extracts in different concentration ( 0 to $1 \mathrm{~g} / \mathrm{l}$ ) were mixed with $100 \mathrm{mM}$ Tris- $\mathrm{HCl}$ buffer $(80 \mu \mathrm{l}, \mathrm{pH} 7.4)$, and $100 \mu \mathrm{l}$ of the DPPH solution. The mixture was shaken vigorously and incubated for $30 \mathrm{~min}$ in the dark at room temperature. The 
absorbance was measured at $517 \mathrm{~nm}$ in a UV/Vis spectrophotometer. Ascorbic acid was used as a positive control. DPPH free radical scavenging ability (\%) was calculated by using the following formula: Inhibition $\%=$ $\left(1-\mathrm{A} / \mathrm{A}_{0}\right) \times 100$ where $\mathrm{A}_{0}$ is the absorbance at $517 \mathrm{~nm}$ of negative control, and $\mathrm{A}$ is the absorbance of mixture containing DPPH and sample.

The ABTS $~^{+}$was produced by $7 \mathrm{mM}$ ABTS stock solution with $2.45 \mathrm{mM}$ potassium persulfate in water, which was kept in the dark at room temperature for $16 \mathrm{~h}$ to give the complete oxidation of ABTS. Before using, the ABTS.$^{+}$solution was diluted with water to get an absorbance of $0.700 \pm 0.050$ at $734 \mathrm{~nm}$. Briefly, $1 \mathrm{ml}$ of ABTS.$^{+}$solution was added to $30 \mu \mathrm{l}$ of extract samples (10 to $200 \mathrm{mg} / \mathrm{l}$ ) and mixed thoroughly. The reaction mixture was incubated at room temperature for $6 \mathrm{~min}$ and the absorbance was immediately recorded at $734 \mathrm{~nm}$. The calibration curve was prepared by trolox solutions.

The $\mathrm{Fe}^{3+}$ reducing power of the extract was determined by the method described by Oyaizu (1986) with a slight modification. Different concentrations (10 to $200 \mathrm{mg} / \mathrm{l})$ of the extract $(0.5 \mathrm{ml})$ were mixed with $0.5 \mathrm{ml}$ phosphate buffer $(0.2 \mathrm{M}, \mathrm{pH} 6.6)$ and $0.5 \mathrm{ml}$ potassium ferricyanide $(0.1 \%)$, followed by incubation at $50^{\circ} \mathrm{C}$ for $20 \mathrm{~min}$. After incubation, $0.5 \mathrm{ml}$ of TCA (10\%) was added to terminate the reaction. The upper portion of the solution $(1 \mathrm{ml})$ was mixed with $1 \mathrm{ml}$ distilled water, and $0.2 \mathrm{ml} \mathrm{FeCl}_{3}$ solution $(0.1 \%)$. The reaction mixture was left for $10 \mathrm{~min}$ at room temperature and the absorbance was measured at $700 \mathrm{~nm}$ against an appropriate blank solution.

\section{Results}

Molecular identification and phylogenetic analysis

A total of 7 sequences of the ITS1-5.8S-ITS2 region of different Gentiana spp. (GQ864021, DQ398633, DQ497573, DQ398636, DQ398661, FJ980363 and JQ890595) collected from the NCBI databases, together with 3 additional ITS of GDF (JQ890597), GA (JQ890596) and GSP (JQ890594) obtained in this study were used for phylogenetic analysis. All ITS were found to be 620-625 bp in length. A BLAST search of the ITS obtained in this study was similar to the ITS of GS (91-94\% similarity, data not shown). However, the phylogenetic analysis based on ITS showed that they belong to different clusters. Three Taiwan-specific Gentiana spp. were phylogenetically different from two major Chinese Longdan (G. scabra, GS and G. triflora) (Figure 2) and close related to another Chinese Longdan (G. rigescens).

\section{Extraction yields}

The ethanol extract yields from six different samples from Gentiana spp. (6.76\%, 5.71\%, 9.10\%, 7.96\%, 24.25\% and $28.05 \%$ for GS, GDF, GA, GSP, dried root 1 (DR1) and dried root 2 (DR2) respectively) were shown in Table 1. Dried roots (DR1 and DR2) which are imported Chinese herbal showed higher extract yields based on the dry weight.

\section{Swertiamarin and gentiopicroside content}

The calibration curves of swertiamarin and gentiopicroside showed good linearity (correlation coefficient = 0.9999 respectively) range from $0.1-100 \mathrm{mg} / \mathrm{l}$ (data not shown). The swertiamarin content in GDA $(2.66 \mathrm{mg} / \mathrm{g})$ and GS $(2.52 \mathrm{mg} / \mathrm{g})$ was the highest, followed by DR1 (1.06 mg/g). Others (GA, GSP and DR2) showed no swertiamarin content. On the other hand, GDF had the highest gentiopicroside $(49.42 \mathrm{mg} / \mathrm{g})$ content while comparing with DR1 (41.17 $\mathrm{mg} / \mathrm{g})$, GS (30.25 mg/g) and DR2 $(9.13 \mathrm{mg} / \mathrm{g})$. There is no gentiopicroside detected in GA and GSP (Table 2).

\section{Total phenolic content}

The total phenolic contents of six sample extracts were determined and are presented in Table 3. The phenolic

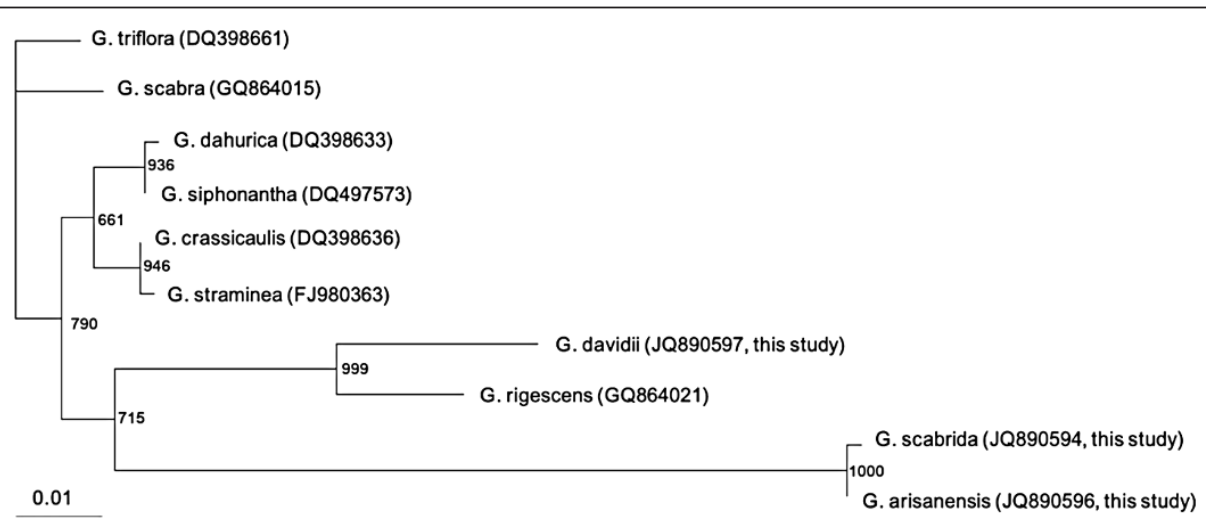

Figure 2 Phylogenetic analysis of six different Gentiana spp. Phylogenetic tree based on the sequences of ITS1-5.8S-ITS2 regions from different Gentiana spp. were constructed by Maximun Parsimony method (1000 bootstrap replicates). 
Table 1 Ethanol extract yields from roots of different Gentiana spp.

\begin{tabular}{lc}
\hline Samples & Extract yield (\%) $^{\mathbf{a}}$ \\
\hline G. scabra (GS) & 6.76 \\
G. davidii var. formosana (GDF) & 5.71 \\
G. arisanensis (GA) & 9.10 \\
G. scabrida var. punctulata (GSP) & 7.96 \\
Gentian dried root 1 (DR1) & 24.25 \\
Gentian dried root 2 (DR2) & 28.05
\end{tabular}

${ }^{a}$ Dry weight basis.

contents were calculated using mg GAE/g dry weight. Significant differences in total phenolic contents were observed in six samples. It ranged from 42.28 to 102.24 mg dry weight. Highest total phenolic content was observed in GSP followed by GDF. GS, GA and DR1 had similar and less content which were less than GSP.

\section{Total flavonoid content}

Flavonoid content of six sample extracts was determined by colorimetric method. Total flavonoid content (expressed as $\mathrm{mg} \mathrm{QE} / \mathrm{g}$ dry weight) ranged from 1.45 to $71.14 \mathrm{mg}$ dry weight (Table 3). Highest total flavonoid content was observed in GSP followed by GS. DR1and DR2 had very low flavonoid content.

\section{Total antioxidant activity}

Free radical scavenging activities of six sample extracts were assessed by the DPPH assay. A significant decrease in the concentration of DPPH radical was observed in Figure 3. The results showed that GSP had the highest DPPH scavenging activity with an IC50 value of $51.41 \mathrm{mg} / \mathrm{l}$. IC50 values of GDF, GA and GS were 106.36, 182.24 and $201.07 \mathrm{mg} / \mathrm{l}$ respectively. Free radical removal capacity for DR1 and DR2 was weak.

Total antioxidant activity of the six sample extracts increased with higher concentration of the extracts.

Table 2 Swertiamarin and gentiopicroside contents in different Gentiana spp.

\begin{tabular}{lcc}
\hline Samples & \multicolumn{2}{c}{ Content (mg/g) } \\
\cline { 2 - 3 } & Swertiamarin & Gentiopicroside \\
\hline G. scabra (GS) & $2.52 \pm 0.03$ A & $30.25 \pm 0.12 \mathrm{C}$ \\
G. davidii var. formosana (GDF) & $2.66 \pm 0.12 \mathrm{~A}$ & $49.42 \pm 2.17$ A \\
G. arisanensis (GA) & N. D. & N. D. \\
G. scabrida var. punctulata (GSP) & N. D. & N. D. \\
Gentian dried root 1 (DR1) & $1.06 \pm 0.03$ B & $41.17 \pm 1.62$ B \\
Gentian dried root 2 (DR2) & N. D. & $9.13 \pm 0.1$ D
\end{tabular}

${ }^{a}$ Value are means \pm standard error, $n=3$. Means followed by the same letter are not significantly different at $5 \%$ level by LSD (least significant difference) test.

N.D.: Not detectable.
Table 3 Total phenolic and total flavonoids contents from ethanol extract of different Gentiana spp. ${ }^{a}$

\begin{tabular}{lcc}
\hline Samples & Total phenolic $^{\mathbf{b}}$ & Total flavonoids $^{\mathbf{c}}$ \\
\hline G. scabra (GS) & $52.34 \pm 0.73 \mathrm{CD}$ & $18.58 \pm 1.30 \mathrm{~B}$ \\
G. davidii var. formosana (GDF) & $66.31 \pm 2.61 \mathrm{~B}$ & $8.06 \pm 0.52 \mathrm{C}$ \\
G. arisanensis (GA) & $42.28 \pm 0.39 \mathrm{D}$ & $9.69 \pm 0.80 \mathrm{C}$ \\
G. scabrida var. punctulata (GSP) & $102.24 \pm 6.18 \mathrm{~A}$ & $71.14 \pm 4.16 \mathrm{~A}$ \\
Gentian dried root 1 (DR1) & $43.17 \pm 1.37 \mathrm{D}$ & $2.66 \pm 0.10 \mathrm{D}$ \\
Gentian dried root 2 (DR2) & $60.59 \pm 1.98 \mathrm{~B}$ & $1.45 \pm 0.14 \mathrm{D}$ \\
\hline
\end{tabular}

Value are means \pm standard error, $n=3$. Means followed by the same letter are not significantly different at $5 \%$ level by LSD (least significant difference) test.

${ }^{b}$ Expressed as mg gallic acid equivalent/g dry weight.

CExpressed as mg quercetin equivalent/g dry weight.

Significant change was observed at 10 to $200 \mathrm{mg} / \mathrm{l}$ concentration of the extract (Figure 4). The total antioxidant activity of $200 \mathrm{mg} / \mathrm{l} \mathrm{GSP,} \mathrm{GDF,} \mathrm{GS,} \mathrm{GA,} \mathrm{DR2} \mathrm{and} \mathrm{DR1}$ sample were $2.85,2.38,2.04,1.73,1.33$ and $1.31 \mu \mathrm{M}$ Trolox Equivalent respectively.

All six samples had shown a considerable amount of reducing activity. The reducing power increased with the higher concentration of gentian extracts and a significant change was observed at 10 to $200 \mathrm{mg} / \mathrm{l}$ concentration (Figure 5). $200 \mathrm{mg} / \mathrm{l}$ of the extracts showed absorbance values of $0.34,0.43,0.58,0.62,0.97$ and 1.93 corresponding to DR2, DR1, GS, GA, GDF and GSP were respectively.

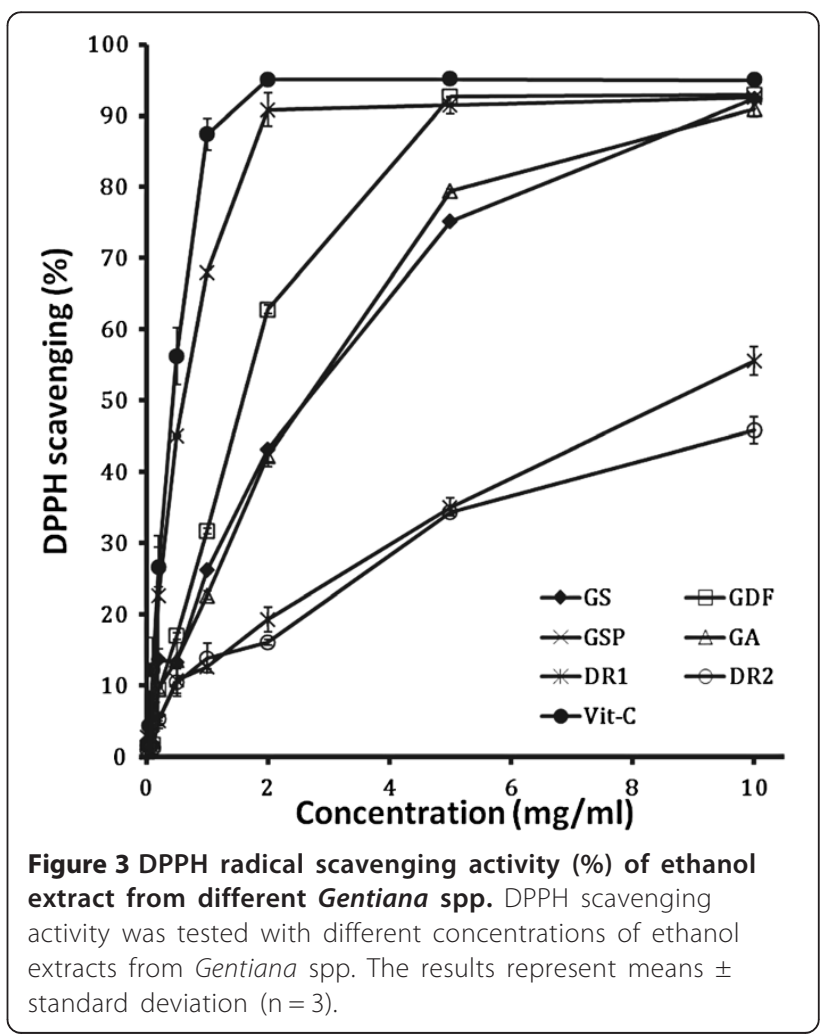




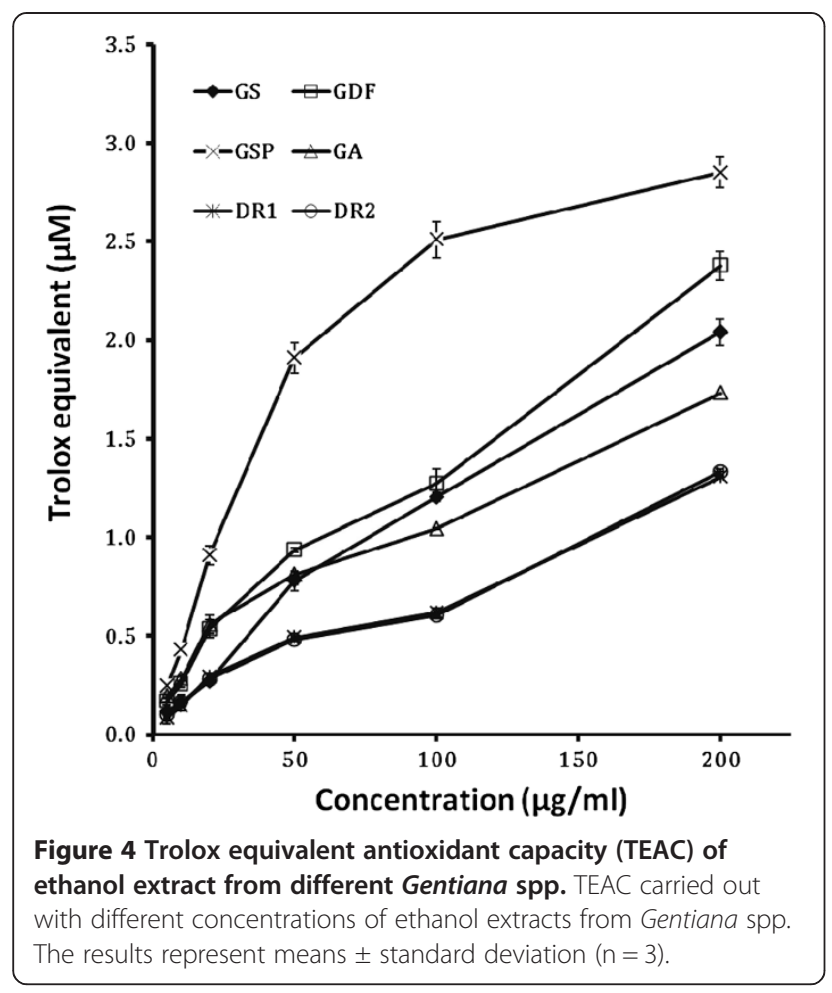

\section{Discussion}

Plants belonging to Gentianaceae are used in wine production or as traditional medicines in many countries. Among them, the roots of G. scabra (GS), G. triflora, G. manshurica and G. rigescens are known as Longdan in

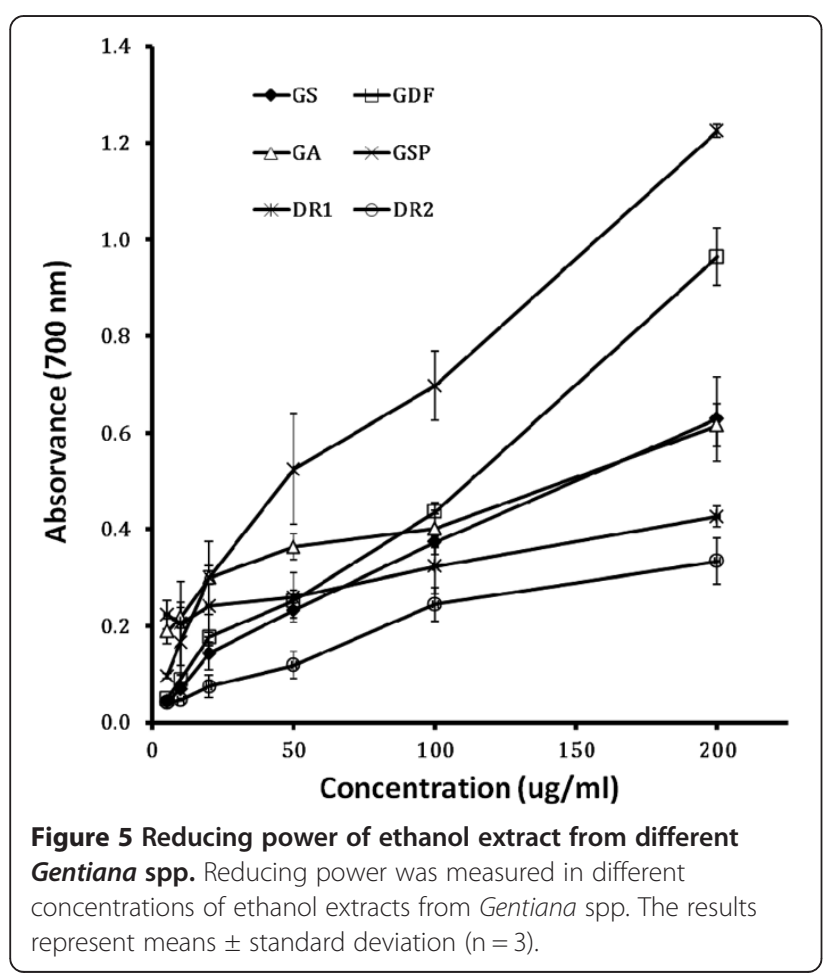

Chinese herbal medicines. While the market demands for Longdan have greatly increased over the past decades, we tried to find the medicinal potential of three Taiwan-specific Gentiana spp.

Based on the ITS of three Taiwan-specific Gentiana spp. (GDF, GA and GSP) obtained in our study, previously published ITS of Longdan (G. scabra (GS), G. triflora, and G. rigescens) and of other Gentiana spp. (G. dahurica, G. siphonantha, G. crassicaulis, and G. strami$n e a)$, we found that all of them showed high similarity to each other. However, phylogenetic analysis based on ITS showed that they belong to different clusters. We observed that GDF, GA and GSP are phylogenetically different from GS (main source of Longdan), hence we said they are Taiwan-specific Gentiana spp.

Based on the results obtained from determination of two active compounds (gentiopicroside and swertiamarin) existed in Longdan, we found 1.5 times more gentiopicroside in GDF than in GS. Moreover, the swertiamarin content in GDF and GS was similar, therefore Taiwan-specific spp. GDF may have medicinal effects potential as Chinese Longdan. Interestingly, DR1 and DR2 (Dried Longdan imported from China) were found with less active compounds than GDF. There is almost no gentiopicroside and swertiamarin in DR2. Probably, DR2 was not the authentic Longdan. Source of dried Chinese herbal is critical in some cases.

Since GDF might have medicinal potential, we tested its antioxidant capacity. Surprisingly GDF showed better antioxidant activity than Chinese Longdan, GS. This result might be correlated to its total phenolic content (66.31 mg GAE/g dry weight). Therefore we tested the DPPH radical scavenging ability and reducing power of GDF, and the results were as good as its antioxidant ability.

GSP (with tall phenotype as described previously (Chen and Wang, 1999) was detected with no gentiopicroside and swertiamarin. This result made it not to be a candidate of Chinese Longdan, however GSP had the strongest antioxidant ability, DPPH radical scavenging ability and reducing power than any others. The main reason for this should be its highest total phenolic (102.24 mg GAE/g dry weight) and flavonoids content (71.14 mg QE/g dry weight) which are 2 times and 4 times higher than Chinese Longdan (GS).

Phenolic compounds are the major constituents in most plants and was reported to possess antioxidant and free radical scavenging activities (Larson, 1988; Olajuyigbe and Afolayan, 2011). And free radicals are correlated to human diseases (Halliwell and Gutteridge, 1990).

Unfortunately, the high total phenolic content in DR1 and DR2 (Dried Longdan imported from China) did not enhance their antioxidant ability and reducing power. 
The possible explanation is the dryness or antibacterial treatment of Chinese herbal had affected our experimental results.

\section{Conclusion}

The results from this study indicate that ITS analysis can be used to identify Taiwan-specific Gentiana spp. And one of the Taiwan-specific Gentiana spp., GDF, was found to posses Longdan specific active compound, and showed higher antioxidant ability and free radical scavenging activities than Chinese Longdan. This data might support the medicinal potential of GDF. Meanwhile, another Taiwan-specific Gentiana spp., GSP, was found to have the strongest antioxidant ability and free radical scavenging activities which might suggest a possible use of GSP as a source of natural antioxidant agents for industrial purpose.

\section{Competing interests}

The authors declare that they have no competing interests.

\section{Authors' contributions}

Prof. HST designed experiment and reviewed the manuscript. Dr. SHH performed the experiments. Prof. EC analyzed the data and prepared manuscript. Prof. CTW and Prof. CLK helped in analyzing data and proof reading of the manuscript. All authors read and approved the final manuscript.

\section{Acknowledgments}

The authors gratefully acknowledged the research grant (NSC 101-2313-B324-001) from the National Science Council, Taiwan.

\section{Author details}

${ }^{1}$ Department of Applied Chemistry, Chaoyang University of Technology, Taichung, Taiwan. Department of Agronomy, National Chung Hsing University, Taichung, Taiwan. ${ }^{3}$ Department of Computer Science and Information Engineering, Providence University, Taichung, Taiwan. ${ }^{4}$ Department of Chinese Pharmaceutical Sciences and Chinese Medicine Resources, China Medical University, Taichung, Taiwan.

Received: 30 October 2013 Accepted: 30 October 2013

Published: 5 November 2013

\section{References}

Aberham A, Schwaiger S, Stuppner H, Ganzera M (2007) Quantitative analysis of iridoids, secoiridoids, xanthones and xanthone glycosides in Gentiana lutea L. roots by RP-HPLC and LC-MS. J Pharm Biomed Anal 45:437-442

Aberham A, Pieri V, Croom JEM, Ellmerer E, Stuppner H (2011) Analysis of iridoids, secoiridoids and xanthones in Centaurium erythraea, Frasera caroliniensis and Gentiana lutea using LC-MS and RP-HPLC. J Pharm Biomed Anal 54:517-525

Blois MS (1958) Antioxidant determinations by the use of a stable free radical. Nature 181:1199-1200

Blokhina O, Virolainen E, Fagerstedt KV (2003) Antioxidants, oxidative damage and oxygen deprivation stress: a review. Ann Bot 91:179-194

Chen CH, Wang JC (1999) Revision of the genus Gentiana L. (Gentianaceae) in Taiwan. Bot Bull Acad Sin 40:9-38

Farber JL (1994) Mechanisms of cell injury by activated oxygen species. Environ Health Perspect 102:7-24

Felsenstein J (1985) Confidence limits on phylogenies: an approach using the bootstrap. Evolution 39:783-791

Felsenstein J (1989) PHYLIP-phylogeny inference package (version 3.2). Cladistics 5:164-166

Georgieva E, Handjieva N, Popov S, Evstatieva L (2005) Comparative analysis of the volatiles from flowers and leaves of three Gentiana species. Biochem Syst Ecol 33:938-947
Halliwell B, Gutteridge JM (1990) Role of free radicals and catalytic metal ions in human disease: an overview. Methods Enzymol 186:1-85

Hudecová A, Kusznierewicz B, Hašplová K, Huk A, Magdolenová Z, Miadoková E, Gálová E, Dušinská M (2012) Gentiana asclepiadea exerts antioxidant activity and enhances DNA repair of hydrogen peroxide- and silver nanoparticlesinduced DNA damage. Food Chem Toxicol 50:3352-3359

Ji K, Liu L, Zhang X, Wang L (2003) Primary study on the electrophoresis atlas of the PCR products of the internal transcribed spacer regions of the rRNA gene from home-planted and wild Gentiana macrophylla, G. straminea. Zhong Yao Cai 26:11-14

Ko HJ, Chen JH, Ng LT (2011) Hepatoprotection of Gentiana scabra extract and polyphenols in liver of carbon tetrachloride-intoxicated mice. J Environ Pathol Toxicol Oncol 30:179-187

Lamaison JLC, Carnet A (1990) Teneurs en principaux flavonoids des fleurs de Crataegeus monogyna Jacq et de Crataegeus laevigata (Poiret D. C) en fonction de la vegetation. Pharm Acta Helv 65:315-320

Larson RA (1988) The antioxidants of higher plants. Phytochemistry 27:969-978

Lin TC, Hsieh CC, Agrawal DC, Kuo CL, Chueh FS, Tsay HS (2007) ITS sequence based phylogenetic relationship of dangshen radix. J Food Drug Anal 15:428-432

Matsukawa K, Ogata M, Hikage T, Minami H, Shimotai Y, Saitoh Y, Yamashita T, Ouchi A, Tsutsumi R, Fujioka T, Tsutsumi K (2006) Antiproliferative activity of root extract from gentian Plant Gentiana triflora on cultured and Implanted tumor cells. Biosci Biotechnol Biochem 70:1046-1048

Olajuyigbe OO, Afolayan AJ (2011) Phenolic content and antioxidant property of the bark extracts of Ziziphus mucronata Willd. subsp. mucronata Willd. BMC Complement Altern Med 11:130

Oyaizu M (1986) Studies on products of browning reactions: antioxidant activities of products of browning reaction prepared from glucoseamine. Jap J Nutr 44:307-315

Re R, Pellegrini N, Proteggente A, Pannala A, Yang M, Rice-Evans C (1999) Antioxidant activity applying an improved ABTS radical cation decolorization assay. Free Radic Biol Med 26:1231-1237

Slinkard K, Singleton VL (1977) Total phenol analysis: automation and comparison with manual methods. Am J Enol Vitic 28:49-55

Tang W, Eisenbrand G (1992) Chinese Drugs of Plant Origin: Chemistry, Pharmacology, and Use in Traditional and Modern Medicine. Springer, Berlin, pp 549-553

Willcox JK, Ash SL, Catignani GL (2004) Antioxidants and prevention of chronic disease. Crit Rev Food Sci Nutr 44:275-295

Wu CT, Gupta SK, Wang AZM, Lo SF, Kuo CL, Ko YJ, Chen CL, Hsien CC, Tsay HS (2012) Internal transcribed spacer sequence based identification and phylogenic relationship of herba Dendrobii. J Food Drug Anal 20:143-151

Zając A, Pindel A (2011) Review of the willow Gentian, Gentiana asclepiadea L. Biodiversity 12:181-185

Zhang XW, Tao Y, Mei LJ, Shao Y (2010) Determination of swertiamarin and gentiopicroside in the flowers of seven gentianaceae. Chin Wild Plant Res 29:38-40

doi:10.1186/1999-3110-54-54

Cite this article as: Huang et al:: Comparative analysis among three Taiwan-specific Gentiana species and Chinese medicinal plant Gentiana scabra. Botanical Studies 2013 54:54.

\section{Submit your manuscript to a SpringerOpen ${ }^{\odot}$ journal and benefit from:}

- Convenient online submission

Rigorous peer review

- Immediate publication on acceptance

- Open access: articles freely available online

- High visibility within the field

- Retaining the copyright to your article

Submit your next manuscript at $>$ springeropen.com 